my paper was written, some of these cases have returned for optical iridectomy and obtained useful vision.

In regard to Dr. Shahan's method of applying heat, it seems to me it might be effective for molerate sized ulcers, but that the resulting scar would not be less in extent than that following other methods of cauterization. In large ulcers it seems to me that to kill the bacteria at the edge of the ulcer sufficient heat would have to be brought to bear to cause considerable opacity in the clear cornea. As he says, sufficient heat to kill bacteria will cause permanent opacity in the rabbit's cornea. This means considerable injury, because the rabbit's cornea has a greater power to clear up than the human cornea.

Dr. William E. ShahnN, St. Louis: Twenty-two cases have been treated by this method since December. Saemisch section was not required in any; none came to enucleation; the process was stopped in all. Final vision acuity depended on the size and situation of the original ulcer. The scar from a small central ulcer caused a greater visual loss than that from a larger peripheral one.

With ulcers larger than the largest point, the point at $158 \mathrm{~F}$. was applied steadily for one minute to a part of the ulcer, then reheated and applied to another part, until all the ulcer had had a contintous application for one minute.

The advantage of this method of thermotherapy over all others is its exactness. We can reproduce the same condition every time and soon learn precisely what to expect. Moreover, heat applied in this way affects not only the surface of the ulcer, but passes dircctly through the cornea into the anterior chamber. This was proved by thermocouple measurements in the paper read at the Detroit session, and its practical value shown in a case of intracorneal abscess due to a perforating wound. There was a pneumococcus infection with hypopyon, etc. The wound closed leaving an abscess which would not heal and could not be reached by surface applications. Two or three one-minute applications of heat at intervals of several days stopped all symptoms and brought about permanent cure. This was a case of Dr. Wiener's.

The additional clouding caused by the heat can be limited accurately to the area of the ulcer and is of negligible importance as compared with an extension of the ulcer.

Several of the cases cured by this method had becn fruitlessly treated with optochin. In fact, most of the cases had been vigorously treated by various methods before the heat treatment was applied. Three rodent (Mooren) ulcers were treated by this method without any benefit. This type of ulcer does not appear to be due to bacterial activity.

Immobilization of Tuberculous Lung by Extraction of Intercostal Nerves.- The Ugeslifif for Lagcr gives a summary, p. 383, of an illustrated article by Warstat in the Deutsche Zcitschrift für Chirurgic describing his success in exclucling the tuberculous lung from participation in respiration by extracting a stretch of each intercostal nerve on that side. Attempts have been made to arrest the functioning of half of the diaphragm by severing the phrenic nerve. But the effect of this is restricted to the lower portion of the lung, while tulserculous processes usually are located in the upper portion. The upper portion can be immobilized by paralyzing the thoracic muscles of respiration. 'He exposes the intercostal nerves from the second to the eleventh, inclusive, his incision being along the margin of the erector spinae. He cuts each nerve distal from the dorsal root, and then twists the distal end of the nerve out with forceps. He applied this operation to sixteen rabbits and one dog, and when killed weeks or months later the lung was found materially reduced in size and of solid consistency. The abdominal muscles did not seem to fecl ally effect from the operation, cither in the animals or in the two clinical cases in which he has applied it. In his first patient that half of the thorax did not participate at all in inspiration, and in three months was much flatter. The patient's condition had improved notably by the end of six months, the tuberculous process having been unmistakably arrested. There was no cavity in the second patient, and the whole set of symptoms disappeared in the course of a few months.

\section{CUFF OPERATION FOR NEPHROPEXY}

\author{
CHARLES M. MCKENNA, M.D. \\ CHICAGO
}

A review of the literature reveals many different methods for kidney fixation. It seems that thus far none has been accepted as a standardized way for this

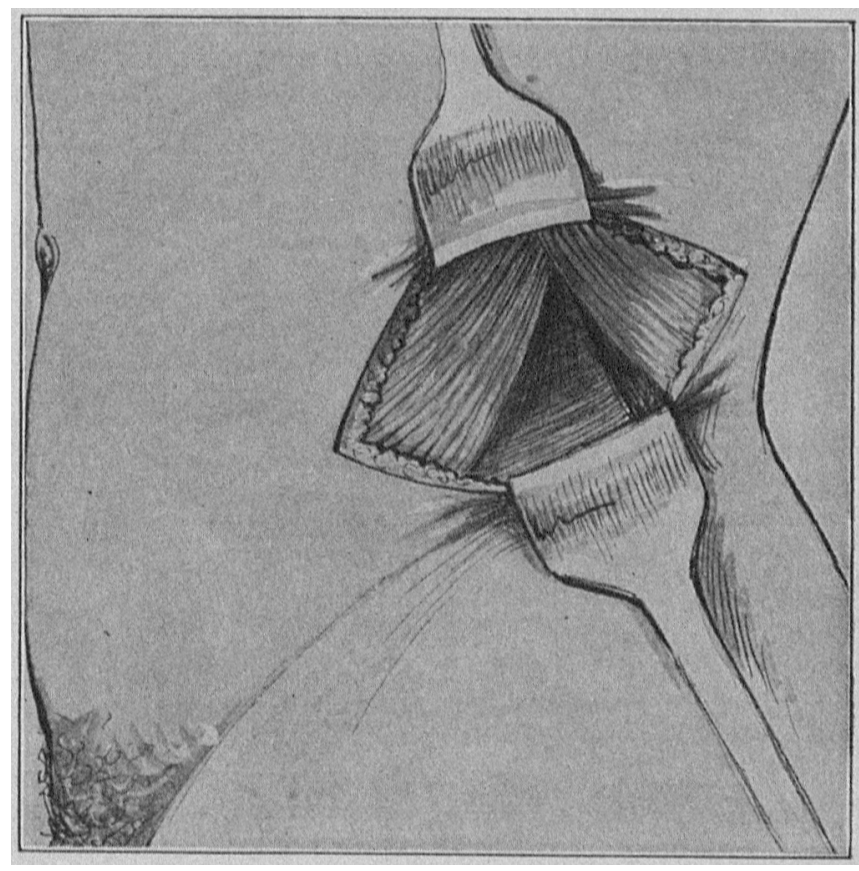

liig. 1.-Finll exposure of Petit's triangle.

operation. Albarran, a French surgeon, suggested the splitting of the capsule, and used it as a layer to make the fixation. Hahn, a German, suggested the splitting of the capsule into four parts. He separated

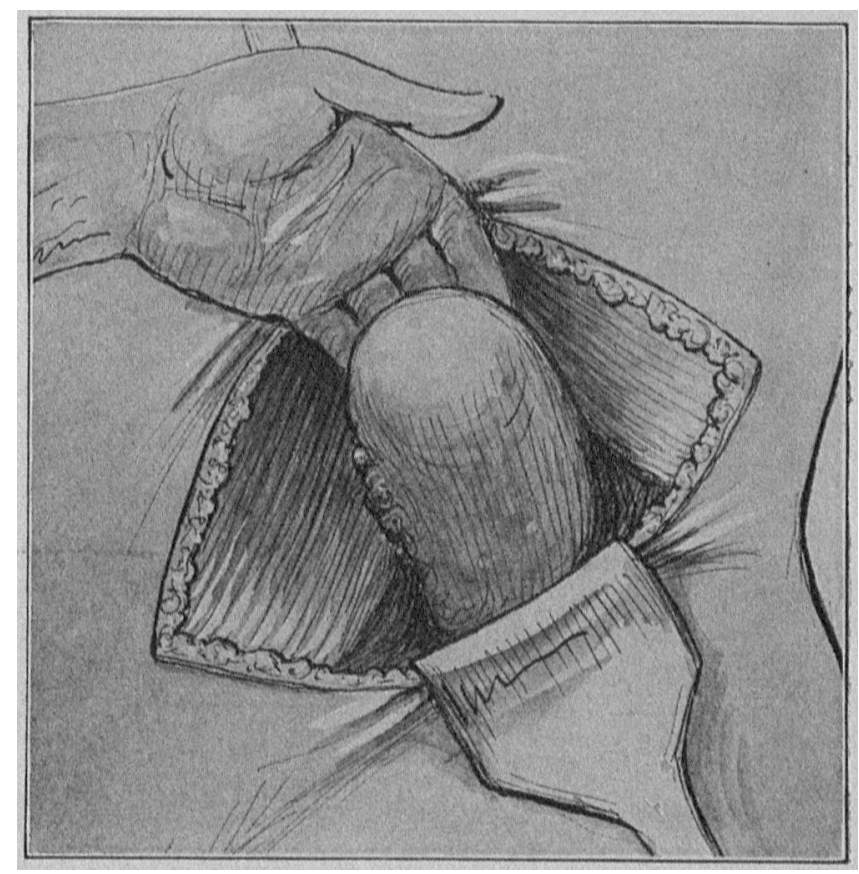

Fig. 2.-Easiest way to deliver kidney, upper pole first.

the capsule longitudinally and divided it so that the upper pole and the lower pole could each be fixed by two anchors. A number of various methods 
could be enumerated, with most of which all are familiar.

The one about to be described is offered as a suggestion. I have used it in a number of cases with

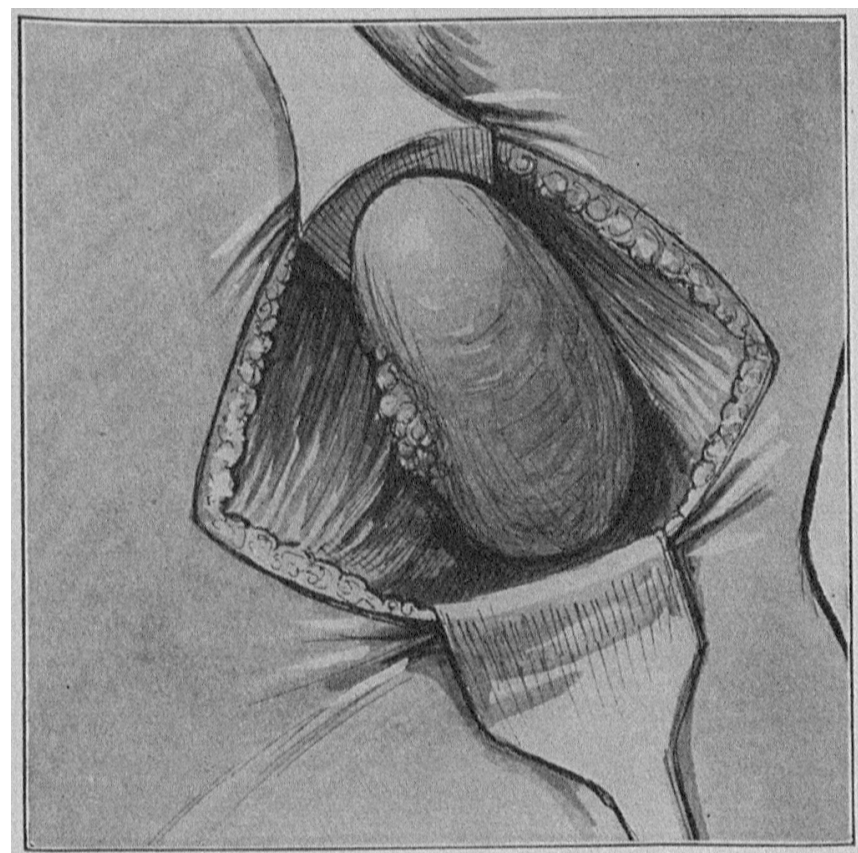

lig. 3.-Free delivery of kidney.

most gratifying results. Petit's triangle is divided and the kidney exposed. The capsule is split from pole to pole and separated carefully on each side of the kidney down to the hilum. If the capsule is fairly

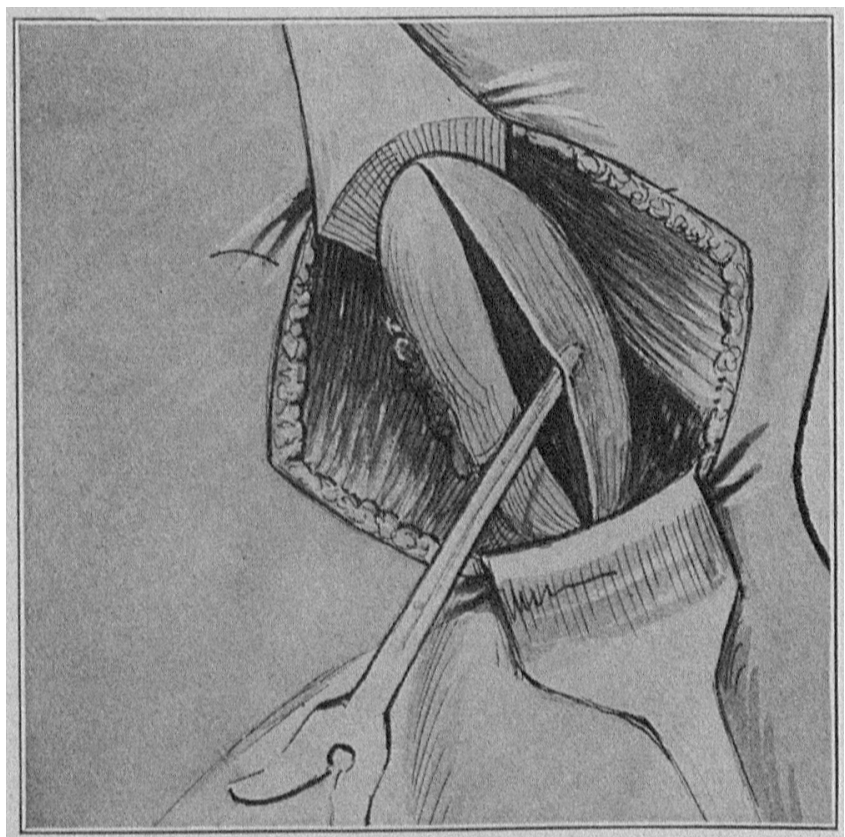

Fig. 4.-Decapsulation of kidney from pole to pole.

firm and thick, the cuff may be made out of three or four thicknesses of the capsule by folding it on itself. Then a mattress suture is introduced through the capsule at both the upper and lower poles on both sides of the kidney, thus malking four strong anchor points. In this method, it is not necessary to decapsulate to the hilum. If the capsule of the kidney is thin, and one fears that the tension would be too grent on the capsule or would allow the suture to pull through or let the kidney go back to its former position, it may be necessary to fold the capsule back on both sides to a point at which they come together, this point being ahove and below the hilum. Here a mattress suture may be inserted at both the apper and lower poles and used for the fixation; this forms a ligament.

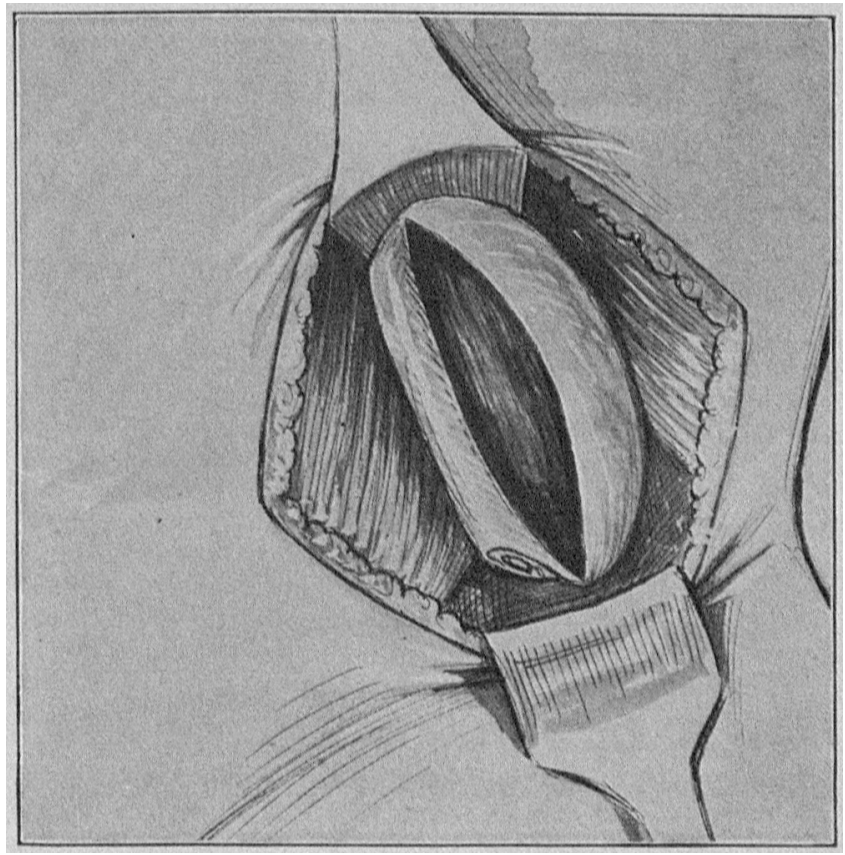

Fig. 5,-Cipsule folded on itself on side of kidney.

It maty been from the illustrations how thick the cipsule is when the two parts are brought together, and what an effective anchorage point can be made

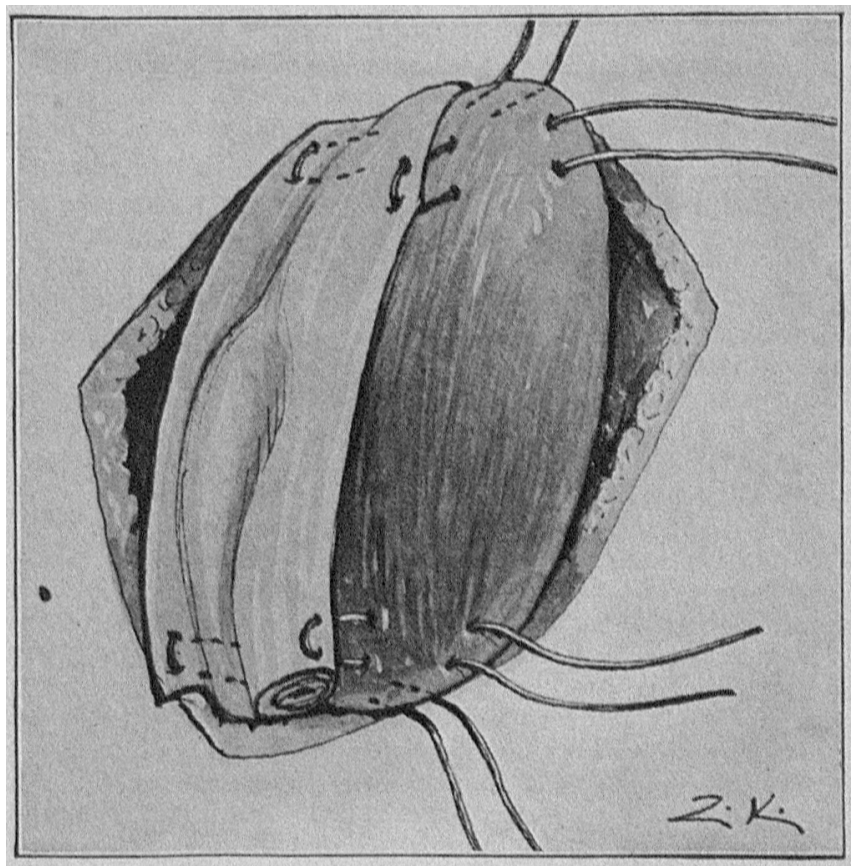

lig. 6.-Kidncy cansule folded and mattress suture in place. The suture could sot be shown as it really is through the kidney parenchyma.

of it with a mattress suture. It will be noted that Hahn used only a single layer of the capsule. Albarran also used a single layer, but used it in four distinct 
anchors. The particular weakness is that the sutures will either pull through, or the capsule will stretch away from the parenchyma of the kidney.

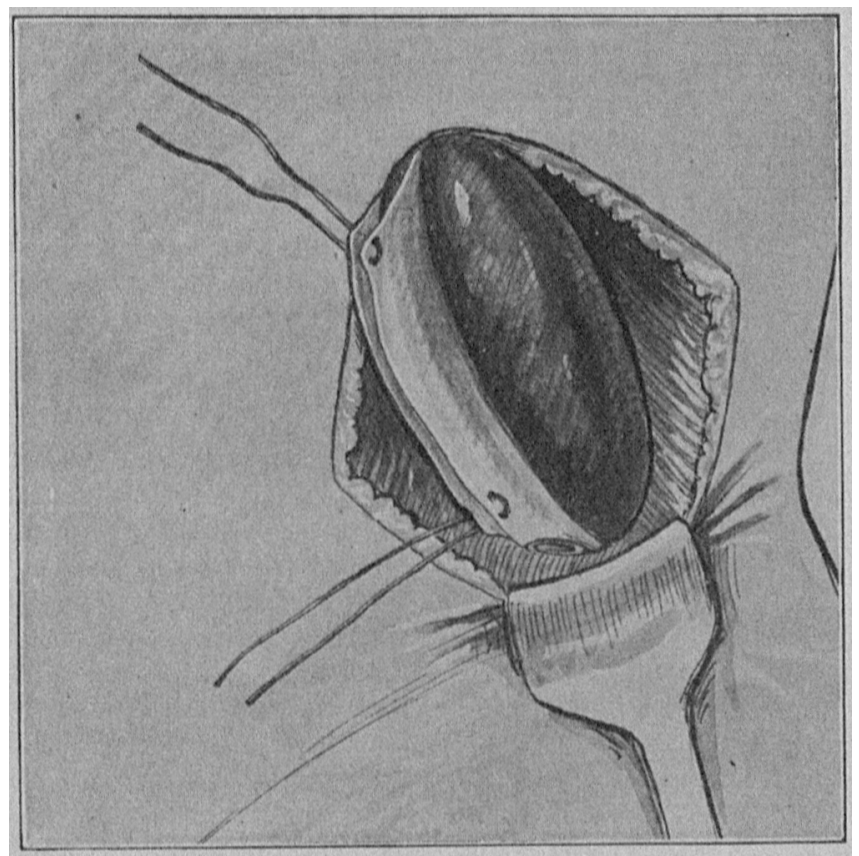

lig. 7.-Calpsule dentuled of hoth sides and brought together as a kiducy ligamest for fixation.

The question may be raised that if a cuff operation is done, the last fold of the capsule next to the kidney would play the same part as in the operation men-

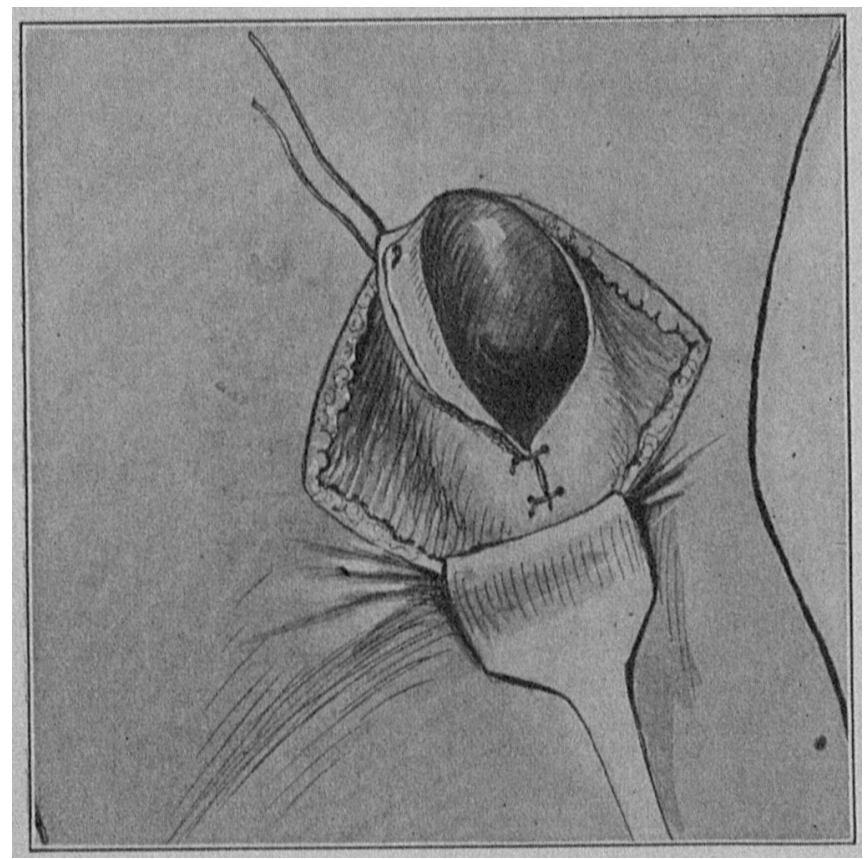

Fig. 8.-Putting kidncy in place and closing wound.

tioned above. This question would come up only when the operation was done without completely decapsulating the kidney down to the hilun and the kidney sutures placed in the folds on each side. This can be easily overcome by placing the sutures through the parenchyma of the kidney, thus holding it firmly to the kidney itsclf. When the capsule is completely denuded as far as the hilum, there is no chance of pulling through, as the folded capsule is too thick an attachment.

After the kidney is put in position and the capsule ligament is sutured firmly to the muscles, the next step of the operation to be taken up is picking up the fatty capsule which has fallen away.

The capsule is brought up over the denuded surface of the kidney and sutured to the muscle. This

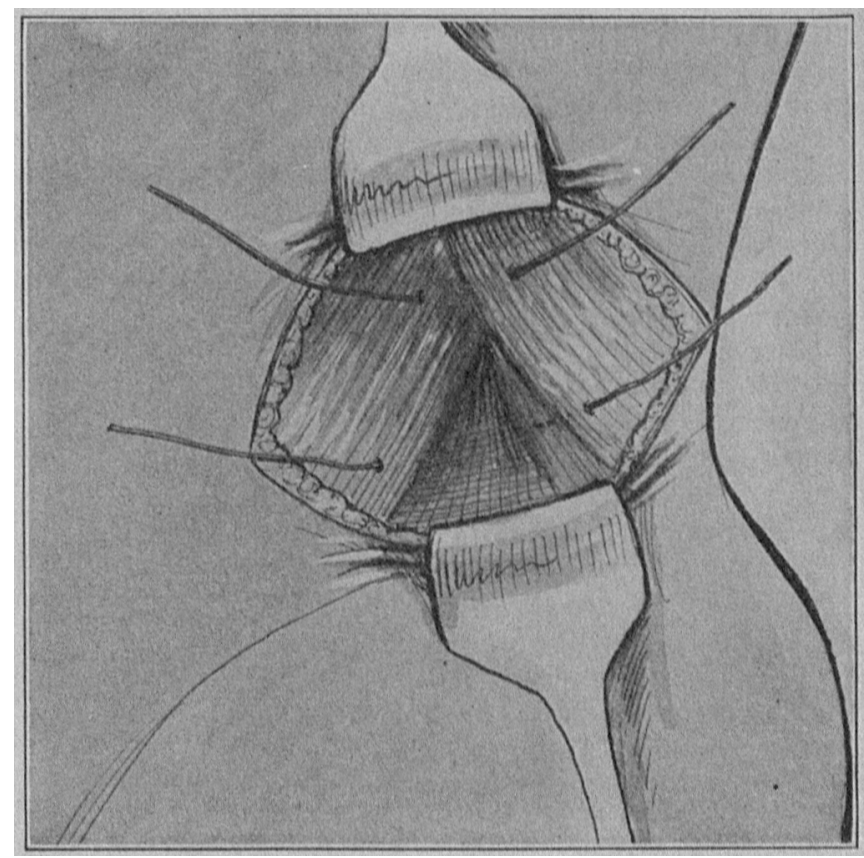

lïig. 9.- $\Lambda_{n}$ ensy and simple method of closing Petit's triangle.

reinforces the fixation by adhesions between the fatty capsule and the kidney proper. The third step consists in placing one or two sutures into the peritoncum

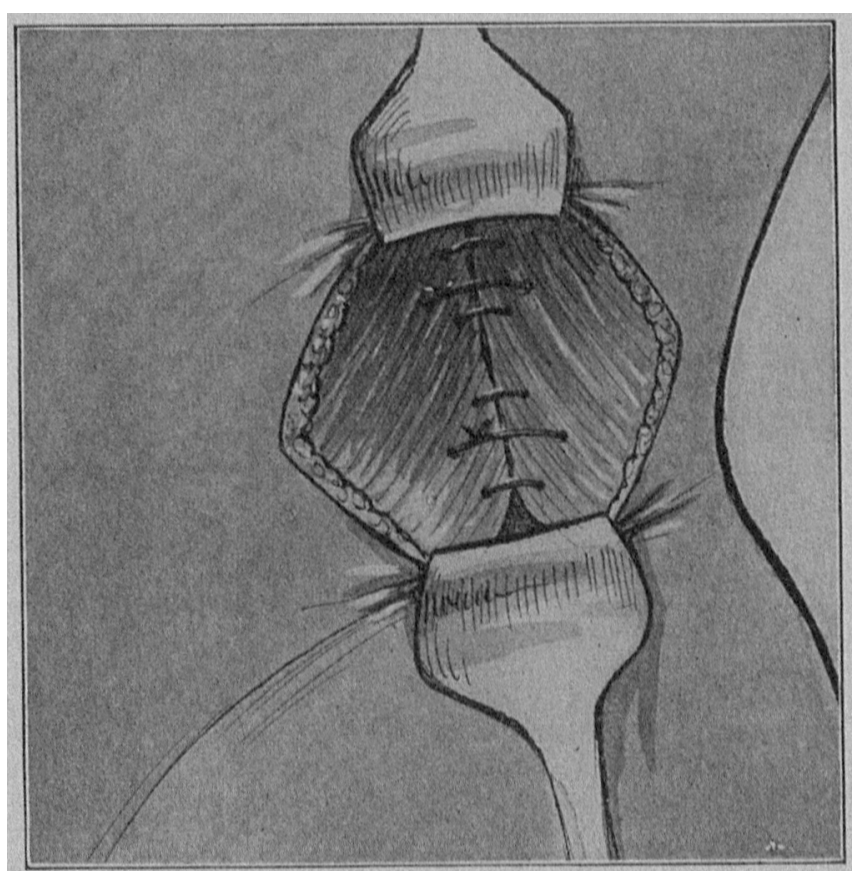

lig. 10.-Improvement over old method of closing kidney incision.

and closing the space underneath the kidney. This is Swenson's suggestion. Thus far we have tried the foregoing technic in six cases with good results. 
The wound is then closed with three or four sutures through Petit's triangle, and the skin is closed with silkworm-gut uninterrupted sutures. The patient is taken back to bed and kept in a recumbent position from ten days to two weeks. At the end of this period, he is allowed to get up and walk about the hospital for three or four days until he has gained sufficient strength to be discharged. It will be noted that the patient has no difficulty in walking about, and is not inconvenienced by having had the operation. This is due, of course, to the method, which employs the division of Petit's triangle instead of a muscle cutting operation, which would cause the patient afterward to walk lopsidedly for some time. It is much easier to deliver the kidney through this incision and make a free exposure than by.the old route. There is less danger of infection, since there has been scarcely any catgut used to tie off bleeding points.

The Petit's triangle incision makes the operation almost bloodless. The folded kidncy capsule forms a ligament and makes a strong cleavage for fixation. The fatty capsule brought up and tied over the denuded surface of the kidney makes a second point of anchorage.

The introduction of two sutures below the kidney through the peritoneum and sutured to the muscle makes the third point of fixation.

The patient is allowed to walk about in.from ten days to two weeks. The patient enjoys the freedom of the side which has been operated on, and suffers no untoward result. This operation is done only when the kidney is well down toward the pelvis and fails to respond to other treatment.

The diet after operation should be nourishing and the same as that given by the internist. The patient is advised not to engage in heavy work for at least one montl after the operation.

25 East Washington Strect.

Handicapping the Intellectually Superior Child.-As intellectually supernormal or superior, we may characterize those children whose present capacity and promise of development point to exceptional mental ability, and who are likely to become leaders in the community. At present they often are as much handicapped in our schools as are their intellectually inferior companions, for whereas the latter are forced beyond the limits of their mental capacity, the former have inadequate opportunity for the expression of their powers. The social importance of specialized treatment, both intellectual and manual, for this group of children is incalculably great. On them human progress chiefly depends. Recently, much attention has wisely and profitably been given to the so-called feebleminded or intellectually weak. We are now beginning to see that, however important this humanitarian work may be, it is even more important that carcful attention and special care be given to the intellectually superior.-Robert M. Yerkes, Mental Hygicnc, April, 1917.

\section{OXYCEPHALUS}

REPORT OF THRLE CASES WITII OPERATION IN ONE*

\section{AR'THUR J. BEDELL, M.D.}

Clinical Professor of Ophthalmology and Otology, Albany Medical College; Attending Oplithalmologist and Otologist, Albany Hospital ALBANY, N. Y.

That oxycephaly has existed for ages is undoubted; that the ocular changes are among the most prominent symptoms is common knowledge; but that a cranial decompression may relieve the intracranial pressure, preserve vision and enable the patient to be a selfsupporting member of society is too little recognized. It is to review the symptoms of three cases and to stimulate interest in this subject on the part of ophthalmologists that this communication is presented.

MacKenzie $^{1}$ in 1854 seems to have been the first to attract attention to cranial deformity as a cause of blindness. Friedenwald, ${ }^{2}$ Fletcher, ${ }^{3}$ Enslin, ${ }^{4}$ Patry ${ }^{5}$ and Hanotten have recorded their experiences in communications of $\mathrm{great}$ valuc. Within the past few months, Sharpe ${ }^{7}$ has presented a paper clearly describing his cases and recording the results of four operations. His paper sliould be read for the reason that only one other worker has published the report of an operation, Fisclsberg of Vienna, although Cushing has performed several operations and will, soon make his report. A similar proceeding has been suggested by several, but their cases were not so treated. I am able to find the records of only seven operations, including the one here reported for the first time.

Symptoms may pass unnoticed, but usually the headache is so severe that it attracts attention, whereupon it is found that the head is deformed and vision failing. The three symptoms of this disease are such as usually to bring these cases to the ophthahmologist primarily: (1) exophthalmos; (2) impairment of vision, and (3) cranial deformity.

* Read before the Section on Ophthalmology at the Sixty. Eighth Annual Session of the American Medical Association, New York, June, 1917.

- Owing to lack of space, this paper is abbrevinted in Tris Journat by onitting some of the illustrations and the bibliographic references. The complete paper will appenr in the Transactions of the section and in the author's reprints.

1. Mackenzic: Practical Treatise on Discases of the Eye, 1854, p. 77 .

2. Fricdenwald: Cranial Deformity and Optic Nerve Atrophy, Am. Jour. Med. Sc., 1893, p. 529; On Optic Nerve Atrophy Associated with Cranial Deformity, Arch. Ophth., 1901, p. 405.

3. Fletcher: On Oxycephaly, Quar. Jour. Med., 1910, p. 385

4. Fnslin: Die Atwenverinderungen beim Turmschïdel besonders die Sehnervencrkrankung, Arch. f. Ophth. (Gracfe's), 1904, p. 151. 5. Patry: Oxycephalic avec cornces à grand axe vertioal, Soc. d'ophth., Paris, March 6, 1906, in Rec. d'ophth., 1906, p. 157.

6. Hanotte: Anatomie pathologique de l'oxycéphalie, Thése de Paris, 1898.

7. Sliatpe: The Cranial Deformity of Oxyecphaly: Its Operative Treatment, witl: a Report of cise's, Am. Jour. Med. Sc., 1916, 151, $\$ 40$. 